Biological and Applied Sciences

Vol.60: e17160326, January-December 2017 http://dx.doi.org/10.1590/1678-4324-2017160326 ISSN 1678-4324 Online Edition

\title{
First Report of Albinism in the Threatened Gillbacker Sea Catfish Sciades parkeri (Siluriformes, Ariidae)
}

\author{
Marcelo C. Andrade ${ }^{1}$, Kurt Schmid ${ }^{1}$, Oswaldo Souza Junior ${ }^{2 *}$, Tommaso Giarrizzo ${ }^{1}$ \\ ${ }^{1}$ Universidade Federal do Pará - Laboratório de Ictiologia do Grupo de Ecologia Aquática, Terra Firme, Belém, \\ Pará, Brasil; ${ }^{2}$ Universidade Federal do Pará, Belém, Pará, Brasil.
}

\begin{abstract}
A sexually mature albino specimen of the Gillbacker Sea Catfish species Sciades parkeri (Siluriformes, Ariidae), a vulnerable species, was captured in northern Amazon estuary, State of Pará, Brazil. Herein we present the first record of albinism phenomenon for this species, including the morphometric description of the albino, and a nonabnormal coloring specimen.
\end{abstract}

Key words: Amazon, delta, estuary, Marajó, vulnerable.

\footnotetext{
*Author for correspondence: oswaldjr@ufpa.br
} 


\section{INTRODUCTION}

The family Ariidae is composed by medium to large sized fish, mainly characterized by its head covered with a bony shield (under a thin skin in most species), with an elongated posterior portion, reaching a nuchal plate $\left[{ }^{1,2}\right]$. In addition, most Ariidae species have usually a bluish gray to yellowish brown coloration, darker dorsally and lighter ventrally - typical catfishes color pattern $\left.{ }^{[1}\right]$. The combination of these features, including internal characters, is very powerful to identify the species. For instance, $S$. parkeri is mostly diagnosed from other Ariidae by having predominantly yellowish brown body coloration with blue tint, swim bladder composed by three chambers, nuchal plate that resembles a shield, granulated exposed bony shield on the head $\left[{ }^{3}\right]$.

The Gillbacker Sea Catfish Sciades parkeri (Traill) is a large Ariidae from brackish and marine waters, distributed along the coast of South America between Venezuela and Brazil, more precisely only up to the Maranhão state coast in Brazil [ $\left.{ }^{4}\right]$. Sciades parkeri constitutes one of the main commercially fished species for supply as food source being found in the northern Brazil and French Guiana markets throughout the year $\left[{ }^{5-7}\right]$. This remarkable catfish species reaches up to $190 \mathrm{~cm}$ of maximum length and has its swim bladder sought after by industry for production of glue, cosmetics and even fermented beverages, which can reach very high market prices $\left.{ }^{4,5}\right]$. Even though widely distributed on coastal waters, $S$. parkeri is a threatened species listed as 'Vulnerable' by the International Union for Conservation of Nature and Natural Resources due to overfishing $\left[{ }^{4}\right]$.

Notwithstanding $S$. parkeri is largely known and frequently captured by artisanal and industrial fisheries along with the Laulao catfish Brachyplatystoma vaillantii (Valenciennes) and the Acoupa weakfish Cynoscion acoupa (Lacepède) [ $\left.{ }^{6}\right]$, it has never before been reported with abnormal coloration.

\section{MATERIALS AND METHODS}

The specimens presented here were caught by an artisanal fishing boat in the brackish waters of the Amazon Estuary Delta, at Marajó Island in the Jurupari channel $\left(00^{\circ} 05^{\prime} 32^{\prime}\right.$ ' S, 49 $9^{\circ} 56^{\prime} 25^{\prime}$ ' W), State of Pará, Brazil (Fig. 1). The sampling was done during daytime using gillnets at an average depth of $15 \mathrm{~m}$ being the captured material stored on ice and posteriorly destined to the local fish market in the county of Vigia $\left(00^{\circ} 51^{\prime} 07^{\prime}\right.$ ' S, $48^{\circ} 08^{\prime} 42^{\prime}$ ' W) (Fig. 1).

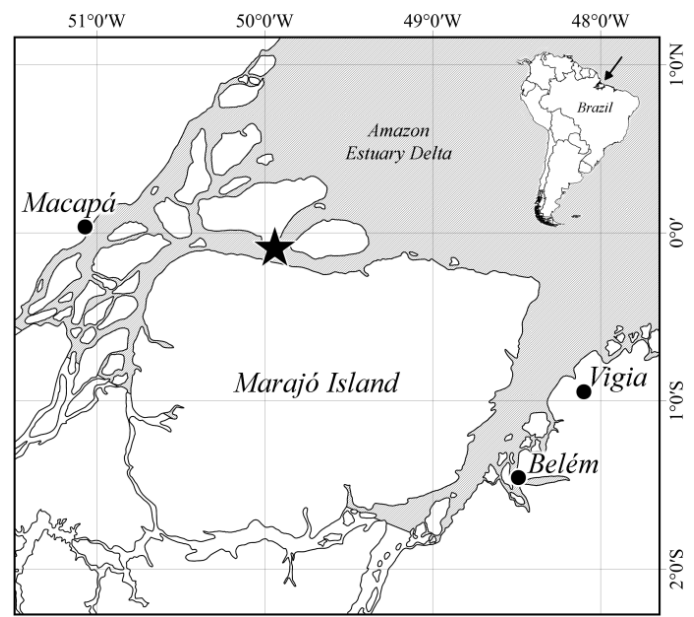

Figure 1. Map of the Amazon Estuary Delta at Marajó Island and the site of capture (star) of the albino specimen of Sciades parkeri. 
Two specimens, one with abnormal and one with normal coloration were assigned to this study. Both were taken to the Laboratório de Ictiologia do Grupo de Ecologia Aquática (GEA) at the Universidade Federal do Pará (UFPA), Belém. The specimens were identified using specific literature (i.e. $\left[{ }^{2,3}\right]$ ), photographed, fixed in $10 \%$ of formaldehyde solution, and posteriorly stored in alcohol at $70 \%$.

Counts and measurements were taken according to the literature $\left[{ }^{3}\right]$, except for the dorsal and pectoral spines lengths, because these have been, as usual, removed by fishermen when captured to avoid accidents $\left[{ }^{5}\right]$. Measurements of specimens were made with a ruler to the nearest $0.1 \mathrm{~cm}$. The subunits of the body are presented as percents of standard length (SL) and total length (TL), and the subunits of head as percents of head length (HL).

The examined material of Sciades parkeri, albino coloring, catalog under GEA 2239 (68.5 cm TL) (Figs. 2a-b), and common color, catalog under GEA $2240(77.0 \mathrm{~cm}$ TL) (Figs. 3a-b).

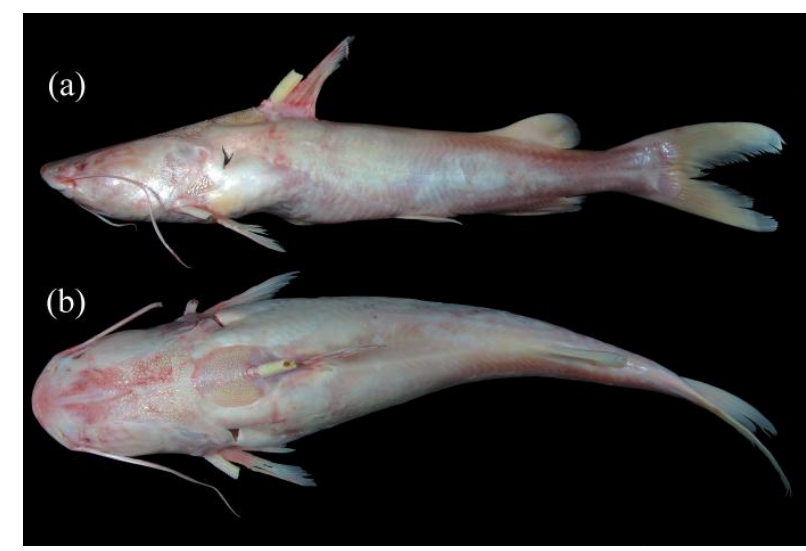

Figure 2. Sciades parkeri, albino specimen; GEA 2239, 68.5 cm TL (a) lateral view, and (b) dorsal view.

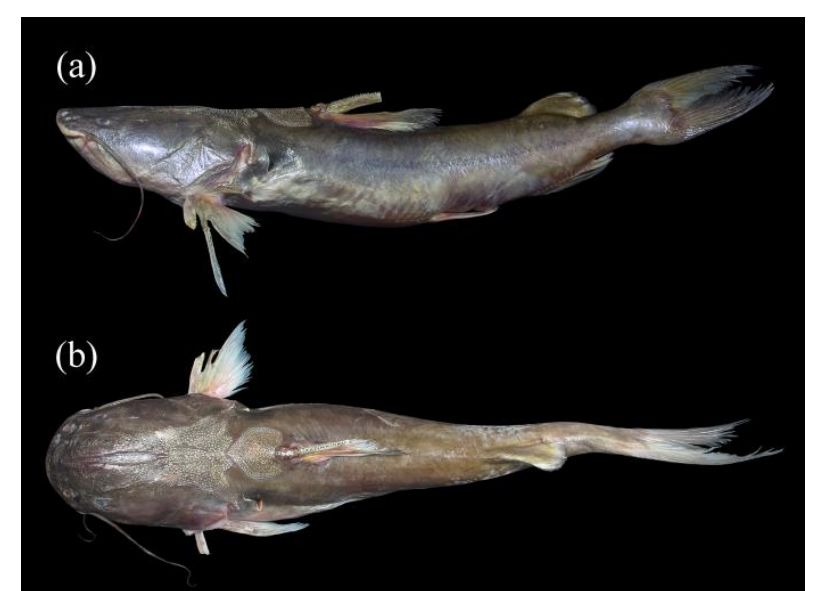

Figure 3. Sciades parkeri, non-abnormal colored specimen; GEA 2240, $77.0 \mathrm{~cm}$ TL (a) lateral view, and (b) dorsal view.

\section{RESULTS AND DISCUSSION}

Morphometric data are presented in Table 1. Adult specimens, eviscerated, unsexed. Body covered by medium to thick leather. General body profile elongated, cylindrical, tapering posteriorly with highest at dorsal-fin origin (Figures 2a, 3a). Head slightly flattened dorso-ventrally with bony shield exposed. Granulated head shield on dorsal region of head (Figures $2 b, 3 b$ ), mainly posteriorly to posterior 
fontanelle. Supraoccipital process more short, wider than long. Nuchal plate immediately after supraoccipital process (Figures $2 b, 3 b$ ), slightly more elongated than wide, tapered anteriorly with concavity posteriorly where the first dorsal-fin spine arises. Eye small, positioned dorso-anteriorly on head, immediately at vertical through to mouth terminus. Two nares, anterior and posterior, not connected by fleshy furrow. Three pairs of barbels, maxillary, mandibular, and mental, gently flattened. Maxillary barbel largest, surpassing slightly pectoral-fin origin; mandibular barbel intermediate sized, reaching operculum membrane; and mental barbel shortest, reaching middle of head. Mouth wide, subterminal, with superior jaw prominent and lunate ventral profile. Dorsal and pectoral spines thick and granulated, intentionally broken. Dorsal with I,7 rays; I,10 pectoral-fin rays; I,6 pelvic-fin rays; I,18-19 anal-fin rays. Adipose fin well-developed, rounded, and teardrop-shaped. Caudal fin forked with lobes equally sized (Figures 2a, 3b).

Table 1 - Morphometric data of two specimens of Sciades parkeri, an albino and a melanic from Jurupari channel, Marajó Island, State of Pará, Brazil.

\begin{tabular}{lcc}
\hline & GEA 2239 & GEA 2240 \\
\cline { 2 - 3 } & Albino & Melanic \\
\hline Total length (mm) & 685 & 770 \\
Standard length (mm) & 567 & 612 \\
Head length (mm) & 155 & 188 \\
& Percents of Total length \\
Maxillary barbel & 25.0 & 21.7 \\
Mandibular barbel & 12.7 & 13.1 \\
Mental barbel & 9.3 & 8.8 \\
& Percents of Standand length \\
Head length & 27.3 & 30.7 \\
Dorsal-fin base & 10.1 & 9.3 \\
& Percents of Head length \\
Snout length & 4 & 6 \\
Mouth width & 8.8 & 10.4 \\
Maxillary barbel & 17.1 & 16.7 \\
Mandibular barbel & 8.7 & 10.1 \\
Mental barbel & 6.4 & 6.8 \\
Anterior internarial distance & 5.1 & 6.4 \\
Interorbital distance & 6.5 & 8.4 \\
Eye diameter & 1.1 & 1.3 \\
Width of supraoccipital process at base & 4.3 & 5.1 \\
Length of supraoccipital process & 2 & 1.3 \\
Width of nuchal plate & 4.7 & 5.6 \\
Length of nuchal plate & 4.3 & 5 \\
\hline
\end{tabular}

Coloration of fresh specimen GEA 2239 with total albinism. Ground coloration pinkish white, more pink to red on dorsum of head at anterior portion of head shield, around mouth and barbels, lips, and base of rays (Figures 2a-b). Nuchal plate, dorsalfin spine, flank immediately posterior of pectoral fin, adipose fin, and caudal fin somewhat yellowish white (Figure 2b). Barbels equally pink. Eye red. Belly completely white. 
In contrast, the specimen GEA 2240 has usual melanism of $S$. parkeri. General coloration countershaded, yellowish brown with gray to blue tint (Figures 3a-b). Dorsal head and flanks darkened, somewhat more blue livid to metallic gray at lateral head and antero-dorsal portion of flanks (Figure 3a), and yellowish brown at head shield, nuchal plate, spines of dorsal fin and portion dorso-posterior of flanks at adipose fin (Figure 3b). Dorsal, adipose and caudal fins with distal portion darkened. Maxillary barbel brown, darker than mental and mandibulary barbels. Iris brownish yellow. Belly pale.

This study presents the first record of albinism in Sciades parkeri, a threatened species $\left[{ }^{4}\right]$, increasing albinism in Ariidae family $\left[{ }^{8,9}\right]$ and expands records for Amazon estuary. Albinism is an inherited condition genetically determined or environmentally induced, that results in little or total absence of pigment in the skin and eyes $\left[{ }^{10,11}\right]$. Although considered rare in vertebrate groups $\left[{ }^{12}\right]$, the albinism in fish is most common, as it is, in Elasmobranchii fishes such as sharks and stingrays (e.g. $\left.\left[{ }^{13-16}\right]\right)$ and also Catfishes, as well as representatives of the families Ariidae, Ictaluridae, Loriicaridae, Pimelodidae and Siluridae $\left[{ }^{8,9}\right]$. It is worth mentioning that it seems more common in Ariidae species that, likewise most sharks and stingrays, inhabit brackish and marine waters, whereas the other aforementioned families inhabit freshwater strictly. On the other hand, in freshwater habitats, albinism occurs frequently in troglobites (i.e. cave species), however, this phenomenon is still poorly understood in cave biology $\left[{ }^{12}\right]$.

Taking into account that albino specimens are more susceptible to predation than non-abnormal colored specimens $\left[{ }^{8}\right]$, it is very interesting that the $S$. parkeri albino reported here has achieved sexual maturity, which is calculated to individuals around 50 to $70 \mathrm{~cm} \mathrm{SL}\left[{ }^{5,7}\right]$. In addition, it is known that albinos have pathological deficiencies, such as weak vision $\left[{ }^{8,16}\right]$, for this reason it is most common in nocturnal fish (i.e.cryptobiotic) such as the Batrachoididae pacuma toadfish $\left[{ }^{17}\right]$ and Anguillidae eels $\left[{ }^{18}\right]$. However, we can expect that the latter is not a major disadvantage for S. parkeri in the Amazon estuary due to the high concentration of suspended sediments thus, nearly zero visibility conditions, obligating fish and other aquatic fauna to depend on other sensory organs.

\section{CONCLUSION}

This study reports the first case of albinism in Sciades parkeri, a threatened species from brackish and marine waters well distributed in the coast between Venezuela and Brazil. The albino coloring specimen recorded is an adult in apparent excellent health. Taking into account that albino specimens are easy preyed, maybe the albino $S$. parkeri reported here has achieved the adult age owing to the protection provided by the murky waters of the Amazon Delta.

\section{ACKNOWLEDGMENTS}

The authors are grateful to team of the Laboratório de Ictiologia do Grupo de Ecologia Aquática (GEA) for their assistance in the management of the specimens utilized in this study. Special thanks to João Torres for making the two S. parkeri specimens available. MCA was funded by CAPES, and KS and TG by CNPq. TG receives productivity grant CNPq and FAPESPA \# 011/2015.

\section{REFERENCES}

1. Cervigón F, Cipriani R, Fischer W, Garibaldi L, Hendrickx M, Lemus AJ, Márquez R, Poutiers JM, Robaina G, Rodriguez B. Fichas FAO de identificación de especies para los 
fines de la pesca. Guía de campo de las especies comerciales marinas y de aquas salobres de la costa septentrional de Sur América. Rome: FAO; 1992. 513 p.

2. Marceniuk AP. Chave para identificação das espécies de bagres marinhos (Siluriformes, Ariidae) da costa brasileira. B Inst Pesca. 2005;31(2):89-101.

3. Betancur-R R, Marceniuk AP, Béarez P. Taxonomic Status and Redescription of the Gillbacker Sea Catfish (Siluriformes: Ariidae: Sciades parkeri). Copeia. 2008;(4):827-34.

4. Betancur-R R, Marceniuk AP, Giarrizzo T, Fredóu FL. Sciades parkeri. The IUCN Red List of Threatened Species [Internet]. 2015 [cited 2015 Jan 1]. p. e.T155018A722547. Available from: http://dx.doi.org/10.2305/IUCN.UK.2015-2.RLTS.T155018A722547.en

5. Léopold M. Poisson de mer de Guyane. Paris: Ifremer; 2004. 214 p.

6. Oliveira DM, Frédou T, Lucena F. A pesca no estuário amazônico: uma análise uni e multivariada. Bol do Mus Para Emilio Goeldi. 2007;2(2):11-21.

7. Mol JH. The freshwater fishes of Suriname. 2nd ed. Leiden: Koninklijke Brill NV; 2012. 890 p.

8. Leal ME, Schulz UH, Albornoz PL, Machado R, Ott PH. First Record of Partial Albinism in two Catfish Species of Genidens (Siluriformes: Ariidae) in an Estuary of Southern Brazil. Brazilian Arch Biol Technol. 2013;56(2):237-40.

9. Wakida-Kusunoki AT, Amador-del-Angel LE. First record of albinism in gafftopsail catfish Bagre marinus (Pisces: Ariidae) from southeast Mexico. Rev Biol Mar Oceanogr. 2013;48(1):203-6.

10. Lawrence E. Henderson's Dictionary of Biology. 2005. 748 p.

11. Fertl D, Rosel PE. Albinism. In: Perrin WF, Würsig B, Thewissen JGM, editors. Encyclopedia of Marine Mammals. 2nd ed. San Diego: Academic Press; 2009. p. 24-6.

12. Romero A. The evolutionary biology of cave organisms. In: Romero A, editor. Cave Biology. Cambridge: Cambridge University Press; 2009. p. 130-58.

13. Bottaro M, Ferrando S, Gallus L, Girosi L, Vacchi M. First record of albinism in the deep water shark Dalatias licha. JMBA2 Biodivers Rec. 2005;5115:4pp. -4pp.

14. Saïdi B, Bradai MN, Marouani S, Guelorget O, Capape C. Atypical characteristics of an albino embryo of Carcharhinus plumbeus (Chondrichthyes: Carcharhinidae) from the Gulf of Gabes (southern Tunisia, central Mediterranean). Acta Adriat. 2006;47(2):167-74.

15. Reum JCP, Paulsen CE, Pietsch T, Parker-Stetter SL. First record of an albino chimaeriform fish, Hydrolagus colliei. Northwest Nat. 2008;89(1):61-2.

16. Wakida-Kusunoki AT. First record of total albinism in southern stingray Dasyatis americana. Rev Biol Mar Oceanogr. 2015;50(1):135-8.

17. Piorski NM, Nunes JLS. A case of albinism in Batrachoides surinamensis (Batrachoidiformes: Batrachoididae) from north-eastern Brazil. Mar Biodivers Rec. 2010;3:e99-e99.

18. Kadir SRA, Rasid MHFA, Wong LL, Kwong KO, Arai T. First record of albinism in a tropical anguillid eel Anguilla bengalensis bengalensis from Malaysia. Mar Biodivers Rec. 2015;8:e114 - Article No.: e114. 